\title{
Reply to the Letter by Kapoor Entitled 'Emerging New Markers of Stroke Risk and Prognosis'
}

\author{
Kensaku Shibazaki \\ Department of Stroke Medicine, Kawasaki Medical School, Okayama, Japan
}

\section{Dear Sir,}

We appreciate the interest of Dr. Kapoor in our article recently published in European Neurology [1]. Brain natriuretic peptide (BNP) is a cardiac neurohormone specifically secreted from the ventricles in response to ventricular volume expansion and pressure overload. Previous studies have shown that the BNP level is related to cardiac function, and it has been used as a biochemical marker of congestive heart failure. BNP levels have also been shown

\section{References}

1 Kapoor S: Emerging new markers of strokerisk and prognosis. Eur Neurol 2014;72:79-80.

-2 Shibazaki K, Kimura K, Sakai K, Fujii S, Aoki J, Saji N: Brain natriuretic peptide on admission as a biological marker of long-term mortality in ischemic stroke survivors. Eur Neurol 2013;70:218-224.

-3 Shibazaki K, Kimura K, Iguchi Y, Okada Y, Inoue $\mathrm{T}$ : Plasma brain natriuretic peptide can be a biological marker to distinguish cardioem- to be elevated in patients with acute ischemic stroke [2-6], in particular, those with atrial fibrillation $[2-4,6]$, and associated with neurological severity [3-5]. Furthermore, we demonstrated that high BNP level is associated with in-hospital mortality [5] or long-term mortality [2] after ischemic stroke. Recently, a rapid (approx. $15 \mathrm{~min}$ ) and easy assay for the measurement of BNP was developed [6]. Therefore, we propose regular BNP mea- surements because BNP level in ischemic stroke patients provides diagnostic or prognostic information which adds to clinical variables and helps guide patient management.

\section{Disclosure Statement}

None. bolic stroke from other stroke subtypes in acute ischemic stroke. Intern Med 2009;48: 259-264.

-4 Okada Y, Shibazaki K, Kimura K, Iguchi Y, Miki T: Brain natriuretic peptide as a predictor of delayed atrial fibrillation after ischaemic stroke and transient ischaemic attack. Eur J Neurol 2010;17:326-331.

5 Shibazaki K, Kimura K, Iguchi Y, Aoki J, Sakai K, Kobayashi K: Plasma brain natriuretic pep- tide predicts death during hospitalization in acute ischaemic stroke and transient ischaemic attack patients with atrial fibrillation. Eur J Neurol 2011;18:165-169.

6 Sakai K, Shibazaki K, Kimura K, Aoki J, Kobayashi K, Fujii S, Okada Y: Brain natriuretic peptide as a predictor of cardioembolism in acute ischemic stroke patients: brain natriuretic peptide stroke prospective study. Eur Neurol 2013;69:246-251.

\section{KARGER}

E-Mail karger@karger.com www.karger.com/ene
(C) 2014 S. Karger AG, Base

0014-3022/14/0722-0081\$39.50/0
Dr. K. Shibazaki, MD

Department of Stroke Medicine Kawasaki Medical School

577 Matsushima, Kurashiki City, Okayama 701-0192 (Japan)

E-Mail shibaken@med.kawasaki-m.ac.jp 